\title{
Characterization of an in vitro model for the study of the short and prolonged effects of myocardial ischaemia and reperfusion in man
}

\author{
Jin-Gang ZHANG', Sudip GHOSH, Colin D. OCKLEFORD* and Manuel GALIÑANES \\ Division of Cardiac Surgery, Department of Surgery, University of Leicester, University Hospitals Leicester NHS Trust, \\ Glenfield Campus, Leicester LE3 9QP, U.K., and *Department of Pre-clinical Sciences, University of Leicester, \\ University Road, Leicester LEI 7RH, U.K.
}

\section{A}

\begin{abstract}
The mechanisms underlying myocardial ischaemia and reperfusion-induced injury have been investigated, mainly by using animal experimental preparations in vitro and in vivo, but little is known of the process in human myocardium. The present studies characterize an in vitro model using human myocardium for the study of early and delayed effects of ischaemia and reperfusion. The right atrial appendage was manually sliced and incubated in buffer through which was bubbled $\mathrm{O}_{2} / \mathrm{CO}_{2}(19: \mathrm{I}, \mathrm{v} / \mathrm{v})$ for various time periods. Lactate dehydrogenase (LDH) leakage, 3[4,5-dimethylthiazol-2-yl]-2,5 diphenyl-2H-tetrazolium bromide (MTT) reduction, oxygen consumption, nucleotide levels and tissue morphology were all investigated as markers of myocardial injury. The specimens remained stable and viable up to $24 \mathrm{~h}$, but had significantly deteriorated by $48 \mathrm{~h}$. The preparation responded to ischaemia in a time-related manner. Tissue viability was reduced by $25 \%$ after $30 \mathrm{~min}$ ischaemia, declined to $60 \%$ after $60 \mathrm{~min}$ ischaemia and to $75 \%$ after $120 \mathrm{~min}$ ischaemia. Interestingly, the tissue was more susceptible when ischaemia was induced after $24 \mathrm{~h}$ of aerobic incubation. The effects of the duration of reperfusion were investigated after a fixed $60 \mathrm{~min}$ ischaemic insult. The results of LDH leakage suggest that reperfusion injury is mainly sustained within the first $2 \mathrm{~h}$ of reperfusion. However, the results of MTT reduction show that there is a progressive decrease in tissue viability over the $24 \mathrm{~h}$ reperfusion period, possibly reflecting the occurrence of tissue necrosis and apoptosis at different reperfusion times. In conclusion, the data provide evidence that the incubation of human atrial tissue in vitro is stable, and slices are viable for at least $24 \mathrm{~h}$, which permits the study of early and delayed consequences of ischaemia and reperfusion in the human myocardium.
\end{abstract}

\section{INTRODUCTION}

Ischaemic heart disease is the single most common cause of mortality in the Western world. Over the last two decades, a great deal has been learned about the pathophysiology of myocardial ischaemia, the consequences of reperfusion and how the adverse effects may be com- batted. Most of our knowledge has been gained by using in vivo and in vitro experimental animal models, and the extrapolation of this information to the human heart has resulted in the implementation of novel therapeutic approaches and in a progressive decrease in the death rate attributed to cardiac ischaemic events.

Studies on cardiac ischaemia and reperfusion in man

Key words: human myocardium, ischaemia, reperfusion, right atrium.

Abbreviations: ANOVA, analysis of variance; LDH, lactate dehydrogenase; MTT, 3-[4,5-dimethylthiazol-2-yl]-2,5 diphenyl-2Htetrazolium bromide; PMNs, polymorphoneutrophils.

${ }^{1}$ Present address: Department of Pharmaceutical Sciences, College of Pharmacy, Washington State University, Pullman, WA 99164-6510, U.S.A.

Correspondence: Professor M. Galiñanes (e-mail mg50@le.ac.uk). 
are difficult because of the presence and potential influence of a whole host of clinical factors. The utilization of human isolated myocytes [1,2], papillary muscle [3,4] and atrial myocardium [5-8] has provided a means to investigate directly the effects and mechanisms of ischaemia and reperfusion in man without the need to resort to assumptions made from animal studies, and to safely test interventions intended to be used clinically. Thus the use of human cultured myocytes [1,9] and right atrial tissue $[5,10]$, for example, has served to identify some of the mechanisms involved in ischaemic preconditioning in the human myocardium, which, compared with those found in other animal species [11-15], has opened the door for its clinical application [16].

The right atrial preparation is of particular interest, because the tissue is easily obtainable from patients undergoing open-heart surgery, it is simple to prepare and the procedure is inexpensive. Yet the preparation has not been fully characterized. The aim of the present studies was therefore to investigate the stability of the human right atrium when incubated in a buffered medium, its response to various degrees of ischaemic insult and the short and prolonged effects of reperfusion.

\section{METHODS}

\section{Preparation of atrial slices}

Specimens of human right atrium appendage were obtained from patients undergoing elective heart surgery. During surgery, the right atrial tissue is routinely removed for venous cannulation and establishment of cardiopulmonary bypass. Samples were quickly immersed in cold $\left(4^{\circ} \mathrm{C}\right) \mathrm{Krebs} /$ Henseleit/Hepes medium $(118 \mathrm{mM} \mathrm{NaCl}, 4.8 \mathrm{mM} \mathrm{KCl}, 27.2 \mathrm{mM} \mathrm{NaHCO}, 1 \mathrm{mM}$

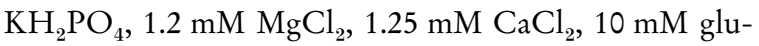
cose, $20 \mathrm{mM}$ Hepes). The medium had been pre-bubbled with $\mathrm{O}_{2} / \mathrm{CO}_{2}(19: 1, \mathrm{v} / \mathrm{v})$ to attain a $P_{\mathrm{O}_{2}}$ of $25-30 \mathrm{kPa}$ and $\mathrm{pH}$ 7.4. The atrial appendage was immediately sliced manually with skin-graft blades (Swann-Morton Ltd, Sheffield, U.K.), each slice to a thickness of $0.5 \mathrm{~mm}$ and a weight of $5-10 \mathrm{mg}$, as originally described for the preparation of rat renal slices [17]. Briefly, the tissue was placed with the epicardial surface face down on filter paper fixed to a rectangular glass base $(5 \times 25 \mathrm{~cm})$. A ground-glass slide $(2.5 \times 7.5 \mathrm{~cm})$ was then pressed against the tissue and the blade was drawn between the slide and the tissue. The slicing apparatus and the tissue was kept wet at all times with ice-cold medium $\left(4-10^{\circ} \mathrm{C}\right)$.

\section{Experimental time course}

After preparation, the slices (3-5 slices per specimen) were blotted with wet filter paper, loaded into glass $25 \mathrm{ml}$ Erlenmeyer flasks and $5 \mathrm{ml}$ of medium, which was

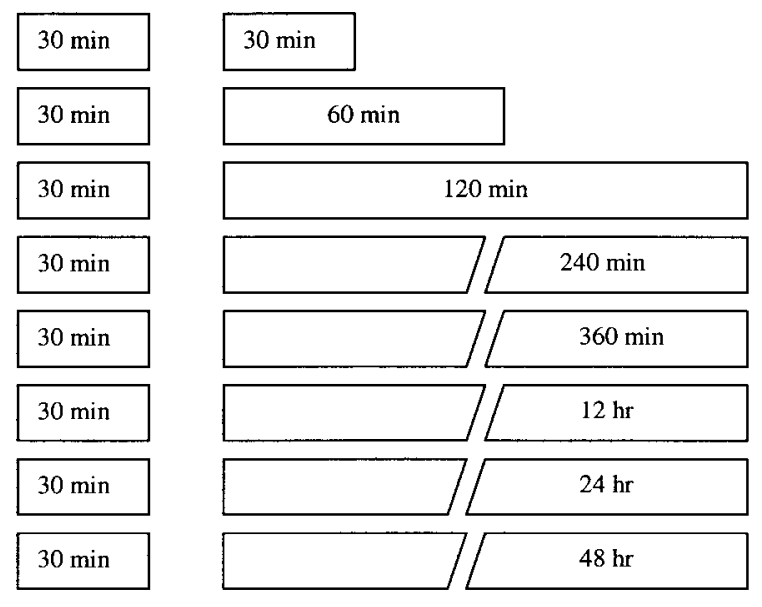

Equilibration

Aerobic Incubation

\section{Figure I Experimental protocol for Study I}

Tissues from Groups I-4 were equilibrated for $30 \mathrm{~min}$ in aerobic conditions at $37^{\circ} \mathrm{C}$. The right atrial slices ( $n=6 /$ group) were further incubated aerobically for the time periods shown.

continuously bubbled with $\mathrm{O}_{2} / \mathrm{CO}_{2}(19: 1)$ to maintain a $\mathrm{PO}_{2}$ of $25 \mathrm{kPa}$ and a pH of 7.4, was added. The flasks were then placed in a shaking water bath $(100$ cycles $/ \mathrm{min})$ at $37^{\circ} \mathrm{C}$ for $30 \mathrm{~min}$ to allow equilibration. The slices were then rinsed with the medium, blotted and placed in clean flasks containing $5 \mathrm{ml}$ of oxygenated medium for various time periods to serve as time-matched aerobic controls.

For the induction of simulated ischaemia, the slices were washed with one rinse of medium bubbled with $\mathrm{N}_{2} / \mathrm{CO}_{2}$ (19:1) at $\mathrm{pH}$ 6.8. In this case, glucose in the medium was replaced with $10 \mathrm{mM}$ 2-deoxy-D-glucose (grade II). The slices were transferred to clean flasks containing $5 \mathrm{ml}$ of the same medium which was continuously bubbled with $\mathrm{N}_{2} / \mathrm{CO}_{2}(19: 1)$ and maintained at $37^{\circ} \mathrm{C}$ during the entire ischaemic period. Monitoring of $\mathrm{P}_{\mathrm{O}_{2}}$ with an oxygen detector electrode (Oxylite Optronix Ltd, Oxford, U.K.) revealed that the $\mathrm{P}_{2}$ in the medium was $0 \mathrm{kPa}$. At the end of each ischaemic period, the non-oxygenated medium was removed, the slices were rinsed with oxygenated medium $\left(\mathrm{O}_{2} / \mathrm{CO}_{2}, 19: 1\right)$ and incubated in $5 \mathrm{ml}$ of oxygenated medium containing $10 \mathrm{mM}$ glucose at $37^{\circ} \mathrm{C}$ for a further $120 \mathrm{~min}$.

\section{Study groups}

Three different studies were performed to investigate: the stability of the preparation (Study 1), the effect of the severity of ischaemia (Study 2), and the effect of the duration of reperfusion (Study 3).

In Study 1 (Figure 1), atrial slices ( $n=6$ /group) were subjected to various periods of aerobic incubation after an initial 30 min equilibration period. At the end of the experimental time, samples of the incubation medium 


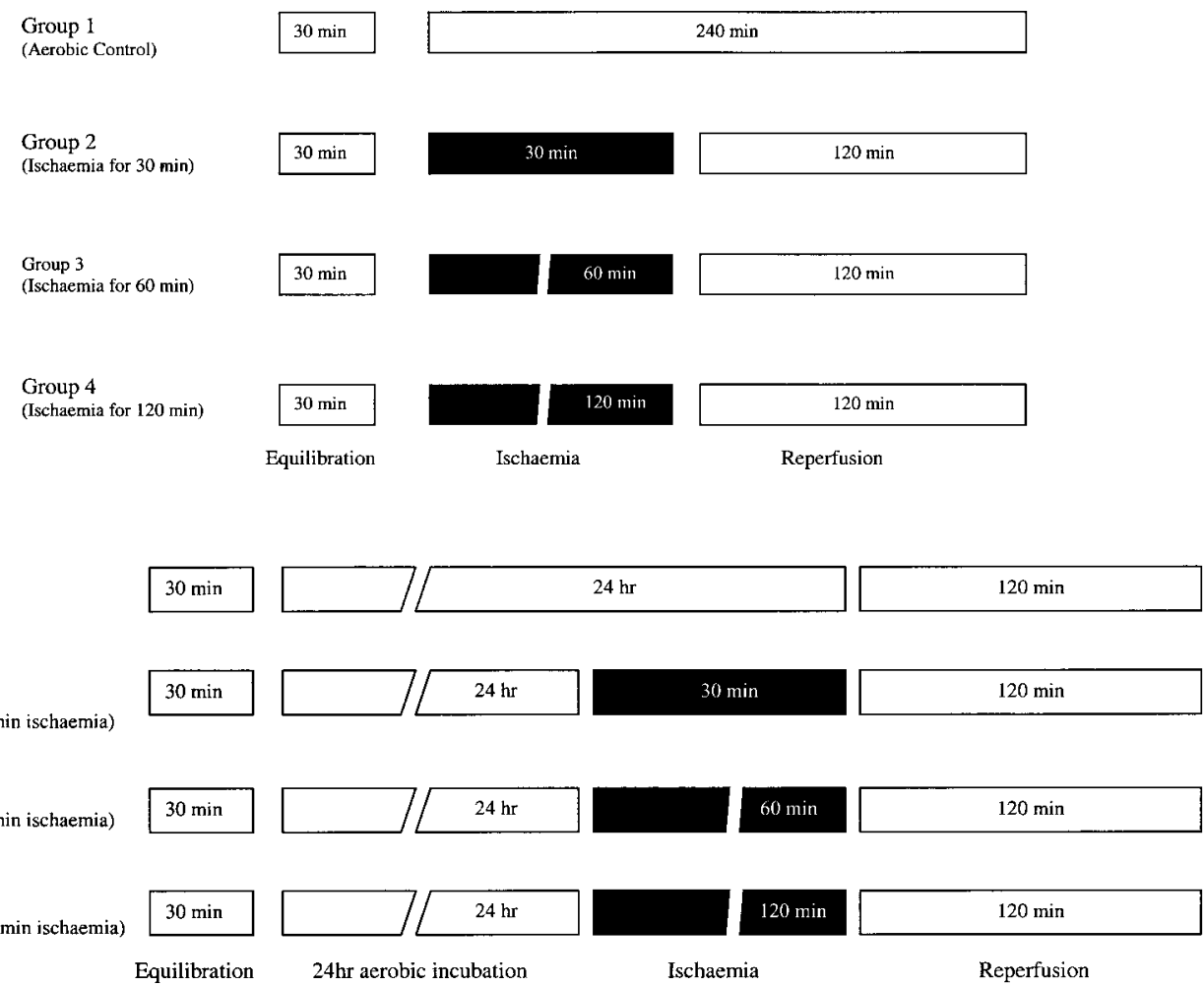

\section{Figure 2 Experimental protocols for Studies 2A and 2B}

Study $2 \mathrm{~A}$ (upper panel): right atrial slices from Groups I-4 ( $n=6 /$ group) were equilibrated for $30 \mathrm{~min}$. In Group I, the slices were then incubated aerobically for $240 \mathrm{~min}$. After $120 \mathrm{~min}$, the incubation medium was changed and the slices were incubated for a further $120 \mathrm{~min}$. In Groups 2, 3 and 4, after equilibration, the slices were subjected to 30,60 or 120 min of ischaemia respectively, and then subjected to $120 \mathrm{~min}$ of reperfusion. Study 2B (lower panel): right atrial slices from Groups $\mathrm{I}-4$ ( $n=6 /$ group) were equilibrated for $30 \mathrm{~min}$. In Group I, the slices were then aerobically incubated for $26 \mathrm{~h}$ to act as time-matched controls. In groups 2,3 and 4, the slices were aerobically incubated for $24 \mathrm{~h}$ before being subjected to 30,60 or $120 \mathrm{~min}$ of ischaemia respectively, followed by $120 \mathrm{~min}$ of reperfusion.

were taken for the assessment of lactate dehydrogenase $(\mathrm{LDH})$ leakage and the slices were removed for the determination of oxygen consumption, tissue viability, nucleotide metabolite analysis and morphological examination.

Study 2 was divided into two parts. In study 2A (Figure 2, upper panel), slices ( $n=6$ /group) were initially equilibrated for $30 \mathrm{~min}$ and then randomly subjected to various periods of ischaemia $(30,60$ or $120 \mathrm{~min})$ followed by 120 min of reperfusion. In Study 2B (Figure 2, lower panel), the slices ( $n=6$ /group) were randomly subjected to an identical protocol of ischaemia and reperfusion as in Study 2A, except that they were incubated aerobically for $24 \mathrm{~h}$ before they were subjected to ischaemia and reperfusion. At the end of the experimental time, samples of the incubation medium were taken for the measurement of $\mathrm{LDH}$ leakage and the slices were used for determination of tissue viability (Studies 2A and 2B) and oxygen consumption (Study 2A only).

In Study 3 (Figure 3), slices ( $n=6$ /group) were subjected to ischaemia for $60 \mathrm{~min}$ and then randomly allocated to various reperfusion times $(2,4,12$ or $24 \mathrm{~h})$. An additional study ( $n=4$ /group) was performed using

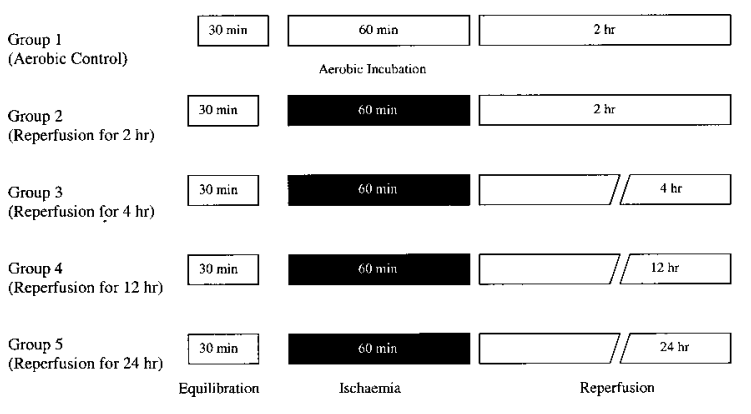

Figure 3 Experimental protocol for Study 3

Right atrial slices from Groups I-5 ( $n=6 /$ group) were equilibrated for $30 \mathrm{~min}$. In Group I the slices were then incubated aerobically for $180 \mathrm{~min}$. In Groups $2-5$ the slices were subjected to 60 min of ischaemia followed by $2,4,12$ or $24 \mathrm{~h}$, respectively, of reperfusion.

the same experimental protocol in the presence of neutrophils obtained from the same patients from whom the right atrial appendage was removed. As in previous studies, LDH leakage and tissue viability were determined at the end of the experimental period. 


\section{Assessment of LDH leakage}

The activity of LDH in the media (units/g wet weight) was assayed spectrophotometrically by monitoring the oxidation of NADH at $A_{340}$ (Sigma Catalogue No. 1340-K).

\section{Tissue viability}

The 3-[4,5-dimethylthiazol-2-yl]-2,5 diphenyl-2H-tetrazolium bromide (MTT) assay was used to quantify tissue viability. In this assay, the yellow MTT is reduced to a blue formazan product by the mitochondria of viable tissue. Briefly, at the end of each experiment, the slices were placed in $15 \mathrm{ml}$ Falcon conical tubes (BecktonDickinson, Franklin Lakes, NJ, U.S.A.), $2 \mathrm{ml}$ of PBS $(0.05 \mathrm{M})$ containing $3 \mathrm{mM}$ MTT (final concentration) was added and the slices were incubated for $30 \mathrm{~min}$ at $37^{\circ} \mathrm{C}$. The slices were then homogenized (Ultra-Turrax T25, dispersing tool G8; IKA Laboratories, Staufen, Germany) in $2 \mathrm{ml}$ of DMSO at $9500 \mathrm{rev} . / \mathrm{min}$ for $1 \mathrm{~min}$ and centrifuged at $1000 \mathrm{~g}$ for $10 \mathrm{~min}$. Portions of the supernatant $(0.2 \mathrm{ml})$ were dispensed into 98 -well flatbottom microtitre plate (Nunc Brand Products, Denmark) and the $A_{570}$ was measured on a plate reader (Benchmark; Bio-Rad, Hercules, CA, U.S.A.) and results were expressed as $A / \mathrm{mg}$ wet weight.

\section{Oxygen consumption}

Oxygen consumption by the slices was measured using a Clark-type oxygen electrode (Rank Brothers, Bottisham, Cambridge, U.K.). The electrode contained $1 \mathrm{ml}$ of airsaturated incubation medium $(\mathrm{pH} 7.4)$ and was maintained at $37^{\circ} \mathrm{C}$. The slices were carefully loaded into the chamber to avoid the formation of bubbles, and oxygen consumption was recorded for 5-8 min. Tissue respiration was calculated as the decrease in oxygen concentration in the medium after the addition of the slices and the results were expressed as nmol $\mathrm{O}_{2} / \mathrm{g}$ wet wt.

\section{Metabolite analysis}

Atrial slices were frozen in liquid nitrogen at the end of $0.5,4,24$ and $48 \mathrm{~h}$ of aerobic perfusion. For tissue metabolite analysis, the dried slices were extracted into $0.6 \mathrm{M}$ perchloric acid ( $25 \mu \mathrm{l} / \mathrm{mg}$ of dry tissue) and the extract was centrifuged at $11000 \mathrm{~g}$ for $5 \mathrm{~min}$ at $4{ }^{\circ} \mathrm{C}$. The supernatant was removed and neutralized with an appropriate volume of $2 \mathrm{M} \mathrm{KOH}$. Aliquots $(20 \mu \mathrm{l})$ were taken for analysis by HPLC [18]. The values obtained ( $\mu \mathrm{mol} / \mathrm{g}$ dry weight) were used to calculate the myocardial energy status (ATP + ADP + AMP).

\section{Morphological examination}

Samples of atrial slices were taken at the end of $0.5,4,24$ and $48 \mathrm{~h}$ of aerobic perfusion and fixed in $3 \%(\mathrm{w} / \mathrm{v})$ glutaraldehyde, post-fixed in $2 \%$ aqueous osmium tetroxide, dehydrated in ethanol and embedded in Araldite resin. A semiquantitative estimate of cell damage was performed on $60-\mathrm{nm}$ sections. Blocks from each tissue sample were randomly chosen and cell damage was quantified without prior knowledge of the group to which the tissue belonged. Cell morphology was assessed according to the following classification $[19,20]$ : grade 1 (normal), compact myofibrils with uniform staining of nucleoplasm, well defined rows of mitochondria between myofibrils and the non-separation of opposing intercalated disks; grade 2 (mild damage), similar to grade 1 , except for the presence of some vacuoles adjacent to the mitochondria; grade 3 (severe damage), reduced staining of cytoplasmic organelles, clumped chromatin, wavy myofibrils and granular cytoplasm or cells with contraction-band necrosis.

\section{Preparation of neutrophils}

Heparinized, venous blood $(4 \mathrm{ml})$ was obtained from patients the day before surgery, in accordance with a protocol approved by the local Ethics Committee. Polymorphoneutrophils (PMNs) were isolated as described previously using Hypaque-Fico density-gradient dextran sedimentation [21]. Purified PMNs were resuspended in PBS and kept on ice until use. PMNs $\left(1 \times 10^{6}\right.$ to $\left.10 \times 10^{6} \mathrm{cells} / \mathrm{ml}\right)$ were added to the atrial slices during the experimental protocol.

\section{Statistical analysis}

Data were expressed as means \pm S.E.M. One-way analysis of variance (ANOVA) was used for comparisons of more than two means. ANOVA for repeated measurements was used to test the significance of mean values over time. A $P$ value of less than 0.05 was considered to be statistically significant.

\section{RESULTS}

\section{Stability of the preparation (Study I)}

\section{LDH leakage}

The leakage of $\mathrm{LDH}$ into the medium during the incubation period is shown in Figure 4. LDH leakage steadily increased during the first $12 \mathrm{~h}$ of incubation, from $2.8 \pm 0.2$ units/g wet wt at $0.5 \mathrm{~h}$ to $10.4 \pm 0.7$ units $/ g$ wet wt at $12 \mathrm{~h}$ (Figure 4, upper panel). However, if the leakage was calculated as the net $\mathrm{LDH}$ leakage (the difference in the enzyme leakage between two adjacent time points divided by the period of incubation in hours), the greatest leakage occurred during the first $0.5 \mathrm{~h}$ $(2.96 \pm 0.31$ units/g wet wt/h) (Figure 4, lower panel), with a continuous decrease in the leakage during the 

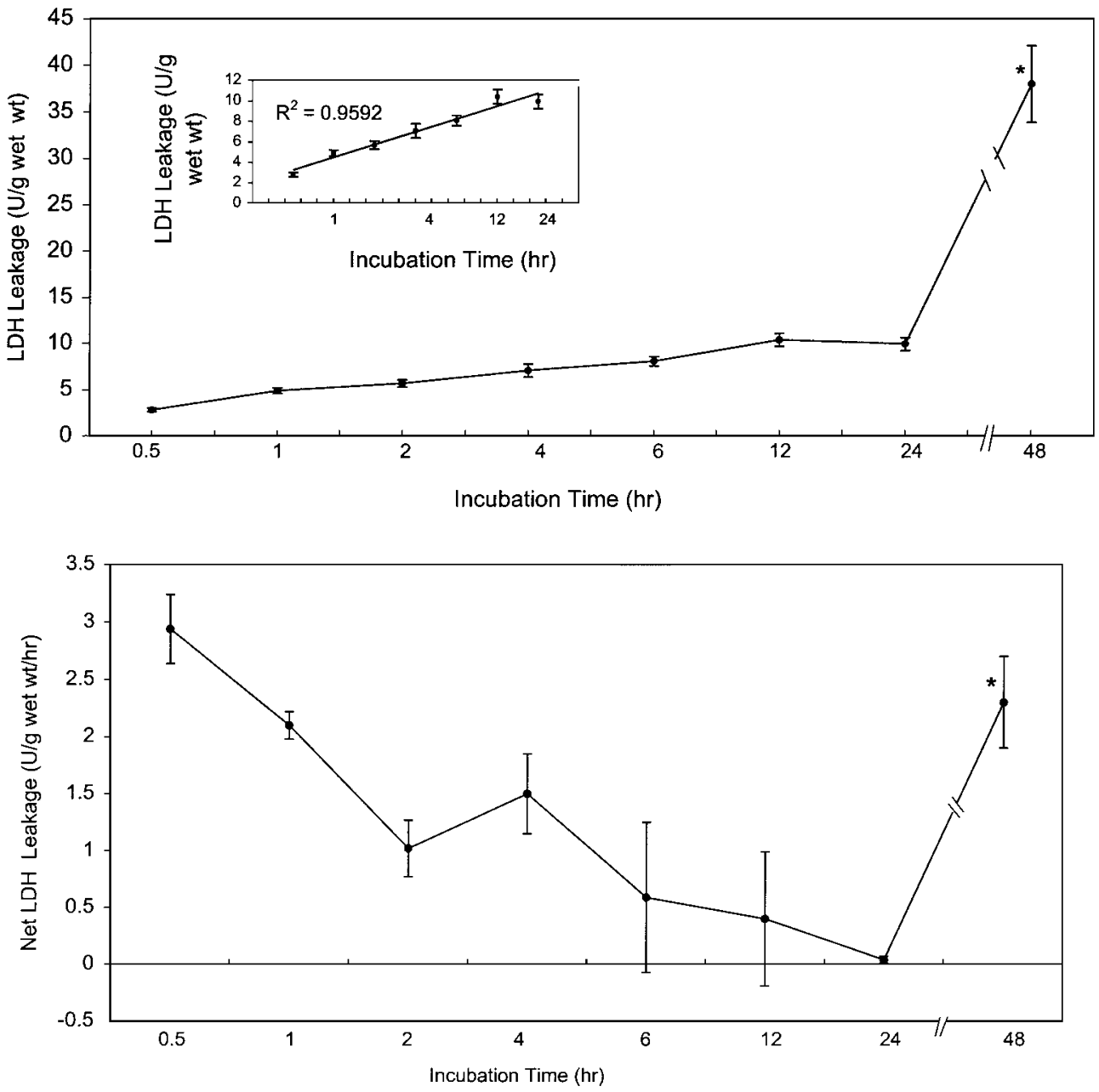

Figure 4 LDH leakage from right atrial slices incubated in aerobic conditions at $37{ }^{\circ} \mathrm{C}$ for different time periods Upper panel: data are expressed as means \pm S.E.M. of six experiments. ${ }^{*} P<0.05$ versus $24 \mathrm{~h}$ value. Inset: linear regression analysis of the data over the $24 \mathrm{~h}$ period. Lower panel: net LDH leakage from right atrial slices. Data are expressed as means \pm S.E.M. of six experiments. ${ }^{*} P<0.05$ versus $24 \mathrm{~h}$ value.

ensuing $12 \mathrm{~h}$. Interestingly, irrespective of the way the results are expressed, there was little $\mathrm{LDH}$ leakage between 12 and $24 \mathrm{~h}$ of incubation, but leakage had dramatically increased at $48 \mathrm{~h}$ of incubation. Regression analysis (inset; Figure 4, upper panel) revealed that the profile of LDH leakage for the first $24 \mathrm{~h}$ of incubation was linear, suggesting continuous enzyme leakage into the media. These results suggest that the preparation does not sustain significant tissue injury for the first $24 \mathrm{~h}$ of incubation but that it has deteriorated by $48 \mathrm{~h}$.

\section{Tissue viability}

The reduction of MTT by the atrial slices (Figure 5), an index of tissue viability, was $0.89 \pm 0.05$ absorbance units/mg wet wt after $30 \mathrm{~min}$ of incubation. These values were not significantly decreased after either $4 \mathrm{~h}$ $(0.84 \pm 0.02$ absorbance units $/ \mathrm{mg}$ wet $\mathrm{wt})$ or $24 \mathrm{~h}$ ( $0.84 \pm 0.03$ absorbance units/mg wet wt). However, by $48 \mathrm{~h}$ these values were significantly decreased to only
$10 \%(0.09 \pm 0.01$ absorbance units $/ \mathrm{mg}$ wet wt; $P<0.05)$ of the values at $30 \mathrm{~min}$ incubation. These results also indicate that the preparation was stable for at least the first $24 \mathrm{~h}$ of incubation but that tissue viability was not maintained for $48 \mathrm{~h}$

\section{Myocardial oxygen consumption}

As shown in Figure 6, oxygen consumption by the slices was approx. $907 \pm 39 \mathrm{nmol} \mathrm{O}_{2} / \mathrm{g}$ wet wt per min after $30 \mathrm{~min}$ of incubation. Similar values were obtained after $4 \mathrm{~h}\left(827 \pm 21 \mathrm{nmol} \mathrm{O}_{2} / \mathrm{g}\right.$ wet wt per min; not statistically different) and $24 \mathrm{~h}\left(876 \pm 40 \mathrm{nmol} \mathrm{O}_{2} / \mathrm{g}\right.$ wet wt/min) of incubation, but again by $48 \mathrm{~h}$ oxygen consumption dramatically decreased to $20 \%$ of the initial values $\left(184 \pm 12 \mathrm{nmol} \mathrm{O}_{2} / \mathrm{g}\right.$ wet wt per $\left.\min ; P<0.05\right)$. These findings further support that the human atrial preparations were viable and stable for at least $24 \mathrm{~h}$ of incubation but not for $48 \mathrm{~h}$. 


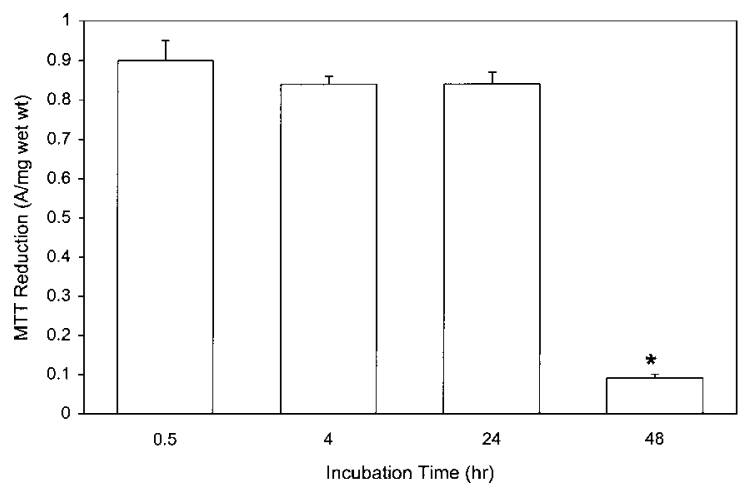

Figure 5 MTT reduction in right atrial slices incubated in aerobic conditions at $37^{\circ} \mathrm{C}$ for different time periods

Data are expressed as means \pm S.E.M. of six experiments. ${ }^{*} P<0.05$ versus the other time periods.

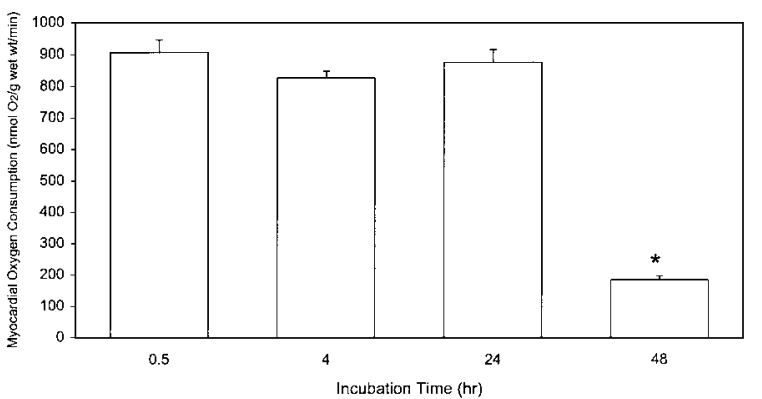

Figure 6 0xygen consumption of right atrial slices in aerobic conditions at $37^{\circ} \mathrm{C}$ for different time periods

Data are expressed as means \pm S.E.M. of six experiments. ${ }^{*} P<0.05$ versus the other time periods.

Tissue adenosine nucleotide content

Table 1 shows the adenosine nucleotide content of the atrial slices at various time periods of aerobic incubation. The ATP, ADP and AMP content, ADP/ATP ratio and the total adenylate pool were similar in the slices aerobically incubated for $0.5,4$ and $24 \mathrm{~h}$. However, in line with the previous results, there was a significant decrease in all metabolites after $48 \mathrm{~h}$ of aerobic incubation.

\section{Morphological assessment}

Figure 7 (upper panels) shows representative high resolution transmission electron micrographs of atrial tissue: grade 1, normal (Figure 7a); grade 2, mild damage (Figure $7 \mathrm{~b}$ ); and grade 3, severe damage (Figure 7c). The morphological appearance of specimens aerobically perfused for $0.5,4$ and $24 \mathrm{~h}$ was similar; however, significant damage was observed in specimens aerobically perfused for $48 \mathrm{~h}$. A semi-quantitative grading of the morphological examination is shown in Figure 7 (bottom panel).

\section{Effect of the severity of ischaemia (Study 2)}

\section{LDH leakage}

As shown in Figure 8 (top panel), ischaemia caused a time-related increase in LDH enzyme leakage from the atrial slices, which was exacerbated when the preparation was incubated for $24 \mathrm{~h}$ before being subjected to ischaemia.

Tissue viability

The level of tissue damage suggested by LDH leakage was mirrored by the MTT reduction results (Figure 8, middle panel). Ischaemia for $30 \mathrm{~min}$ significantly decreased the ability of the slices to reduce MTT to $75 \%$ of the aerobic control mean values, with a further decrease when the period of ischaemia was extended to 60 or 120 min. Again, viability was even less when the tissue was incubated for $24 \mathrm{~h}$ prior to ischaemia.

\section{Oxygen consumption}

As shown in Figure 8 (bottom panel), oxygen consumption by the atrial slices was significantly decreased by $30 \mathrm{~min}$ of ischaemia, to almost $50 \%$ of the aerobic control values. However, in contrast with the pattern observed for LDH leakage and MTT reduction, the increase in ischaemic time was not accompanied by a

Table I Adenosine nucleotide content ( $\mu \mathrm{mol} / \mathrm{g}$ dry wt) of right atrial slices subjected to aerobic perfusion at $37{ }^{\circ} \mathrm{C}$ for various time periods

${ }^{*} P<0.05$ versus 0.5 h aerobic incubation group.

\begin{tabular}{|c|c|c|c|c|c|c|}
\hline \multirow{2}{*}{$\begin{array}{l}\text { Period of aerobic } \\
\text { incubation }\end{array}$} & \multirow[b]{2}{*}{$n /$ group } & \multicolumn{3}{|l|}{ Nucleotide } & \multirow[b]{2}{*}{ ADP/ATP ratio } & \multirow[b]{2}{*}{ Total adenylate pool } \\
\hline & & ATP & ADP & AMP & & \\
\hline $0.5 \mathrm{~h}$ & 6 & $5.56 \pm 0.80$ & $3.52 \pm 0.35$ & $0.73 \pm 0.19$ & $0.45 \pm 0.15$ & $9.80 \pm 1.97$ \\
\hline $4 \mathrm{~h}$ & 6 & $5.50 \pm 0.55$ & $4.54 \pm 0.27$ & $1.03 \pm 0.33$ & $0.52 \pm 0.14$ & $10.65 \pm 1.05$ \\
\hline $24 \mathrm{~h}$ & 6 & $4.30 \pm 0.42$ & $3.38 \pm 0.27$ & $0.61 \pm 0.12$ & $0.46 \pm 0.11$ & $8.17 \pm 0.89$ \\
\hline $48 \mathrm{~h}$ & 6 & $2.16 \pm 0.73^{*}$ & $1.07 \pm 0.15^{*}$ & $0.16 \pm 0.06^{*}$ & $0.23 \pm 0.04^{*}$ & $3.40 \pm 1.36^{*}$ \\
\hline
\end{tabular}



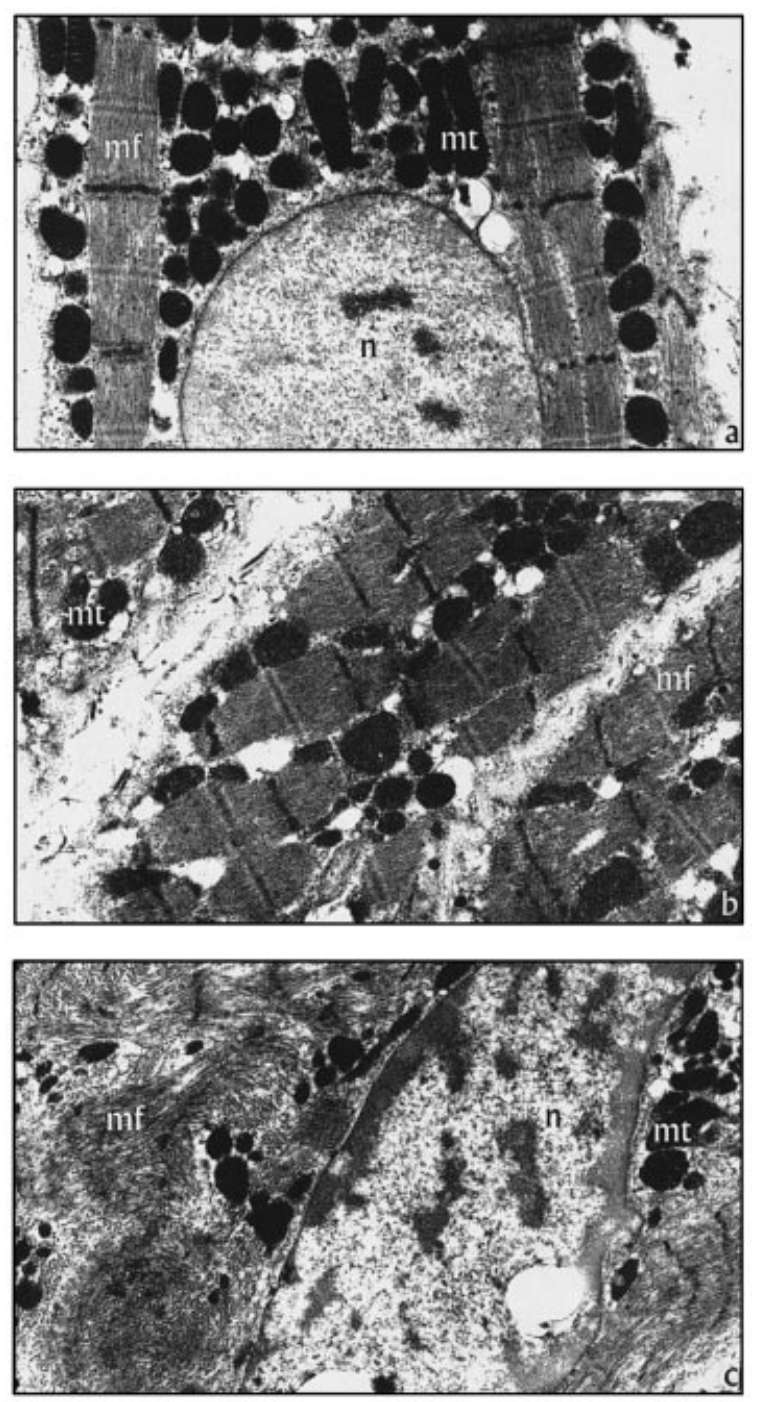

$\stackrel{1 \mu \mathrm{m}}{ }$

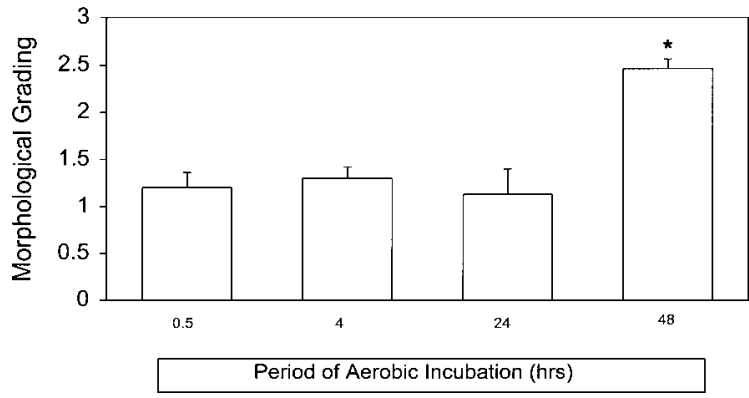

Figure 7 Representative transmission electron micrographs showing morphological changes in right atrial slices incubated in aerobic conditions for different time periods

Upper panel: (a) normal tissue, grade I; (b) mild damage, grade 2; (c) severe damage, grade 3 (see text for details). n, nucleus; mf, myofibril; mt, mitochondria. Scale bar $=\mathrm{I} \mu \mathrm{m}$ (applies to each panel). Lower panel; semiquantitative assessment of tissue damage after aerobic incubation for various time periods. Data are expressed as means \pm S.E.M. of six experiments. ${ }^{*} P<0.05$ versus rest of the groups.
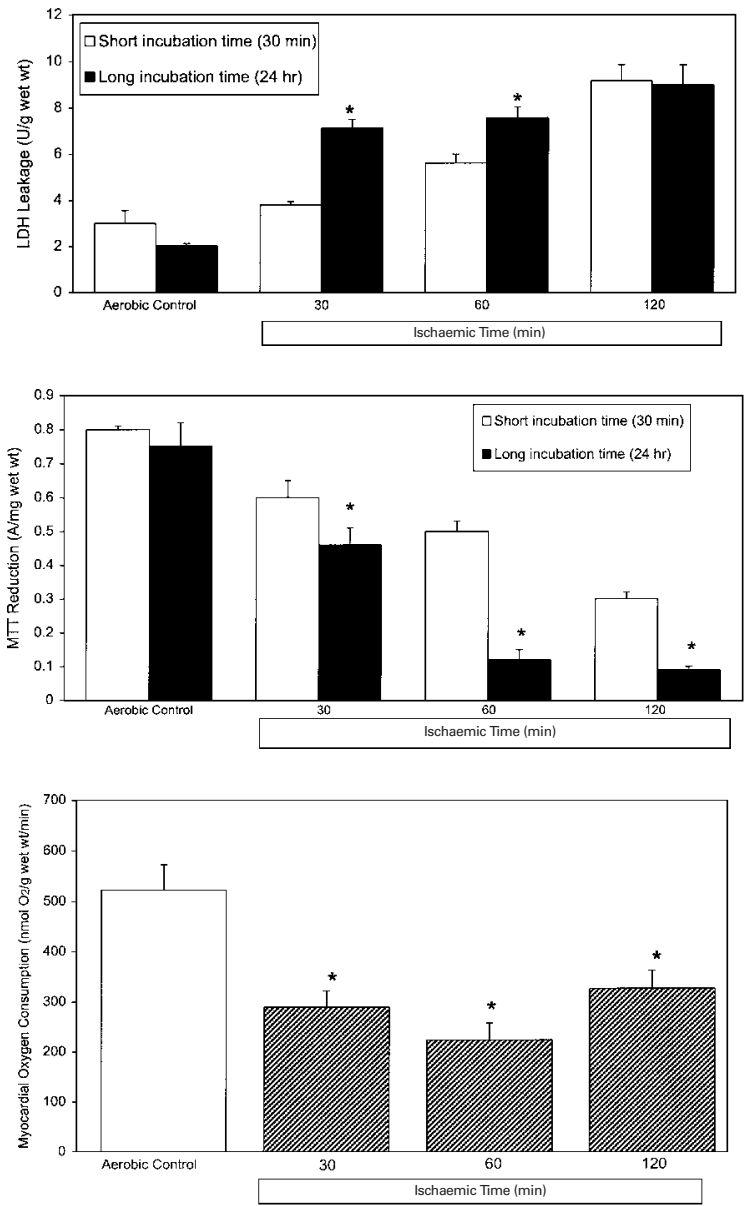

Figure 8 Effect of ischaemia/reperfusion of right atrial slices on LDH leakage, MTT reduction and oxygen consumption

Top panel: LDH leakage (units/g wet wt) from right atrial slices is shown after 30 , 60 or $120 \mathrm{~min}$ of ischaemia followed by $120 \mathrm{~min}$ reperfusion for short or long incubation times. Data are expressed as means \pm S.E.M. of six experiments. ${ }^{*} P<$ 0.05 versus the corresponding short incubation time group. Middle panel: MTT reduction by right atrial slices after 30,60 or 120 min of ischaemia followed by 120 min reperfusion for long or short incubation times. Data are expressed as means \pm S.E.M. of six experiments. ${ }^{*} P<0.05$ versus the corresponding short incubation time group. Bottom panel: oxygen consumption by right atrial slices after 30,60 or 120 min of ischaemia followed by 120 min reperfusion for $30 \mathrm{~min}$ (short) incubation time. Data are expressed as means \pm S.E.M. of six experiments. ${ }^{*} P<0.05$ versus aerobic control.

commensurate decrease in oxygen consumption and the mean values after 60 or 120 min of ischaemia were not significantly different from those observed after $30 \mathrm{~min}$ ischaemia.

\section{Effect of the duration of reperfusion (Study 3)}

In this study, the period of ischaemia was $60 \mathrm{~min}$ in all groups but the atrial muscle slices were reperfused for 2, 4,12 or $24 \mathrm{~h}$. 

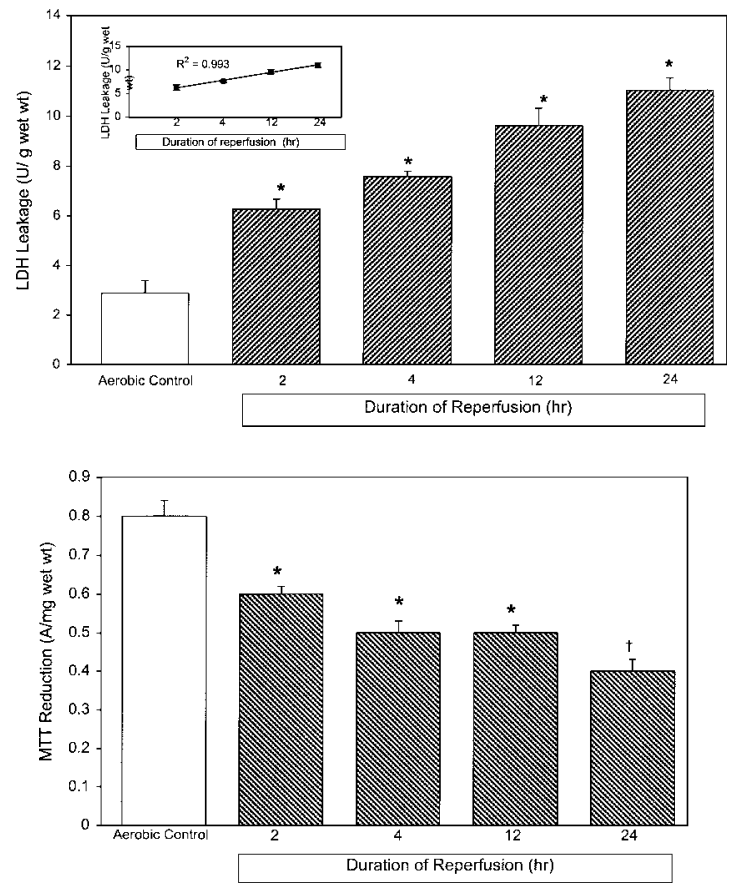

Figure 9 Effect of different periods of reperfusion after $60 \mathrm{~min}$ of ischaemia on LDH leakage from and MTT reduction by right atrial slices

Upper panel inset: linear regression analysis of the LDH values during the different periods of reperfusion. Data are expressed as means \pm S.E.M. of six experiments. ${ }^{*} P<0.05$ versus aerobic control; $\nmid P<0.05$ versus rest of the groups.

\section{LDH leakage}

Figure 9 (upper panel) shows that LDH leakage gradually increased with the duration of reperfusion; however, as shown in Study 1, this increase may represent the overall accumulation of the enzyme rather than net release of LDH. Thus regression analysis (Figure 9, inset) revealed an LDH leakage profile similar to that seen in Study 1.

The LDH leakage profile was similar to controls when atrial slices were incubated in the presence of neutrophils for the first $12 \mathrm{~h}$ of reperfusion; however, after $24 \mathrm{~h}$ of reperfusion, LDH leakage was substantially increased when compared with the group without neutrophils $(20.32 \pm 0.64$ versus $11.02 \pm 0.5$ units $/ g$ wet wt respectively; $P<0.05)$.

\section{Tissue viability}

As shown in Figure 9 (lower panel) and in Study 2, ischaemia for $60 \mathrm{~min}$ followed by $120 \mathrm{~min}$ reperfusion significantly decreased MTT reduction by atrial slices. Interestingly, and in contrast with the $\mathrm{LDH}$ leakage results, extension of the reperfusion period beyond $2 \mathrm{~h}$ revealed a delayed reperfusion injury with three possible phases: the first corresponding to the initial $2 \mathrm{~h}$, the second observed between 4 and $12 \mathrm{~h}$ of reperfusion and the third manifesting after $24 \mathrm{~h}$, where the mean MTT reduction values decreased to $50 \%$ of the aerobic control values.

An identical profile of MTT reduction by atrial slices was observed for the first $12 \mathrm{~h}$ of reperfusion in the presence of neutrophils, but a greater decrease was seen after $24 \mathrm{~h}$ of reperfusion than was observed in the group without neutrophils $(0.10 \pm 0.04$ versus $0.40 \pm 0.02$ absorbance units/mg wet wt respectively; $P<0.05$ ).

\section{DISCUSSION}

The present studies have demonstrated that the incubation of human atrial slices in a buffered medium is a useful preparation for the investigation of the mechanisms of injury underlying myocardial ischaemia and reperfusion in man. The preparation was stable and viable for at least $24 \mathrm{~h}$, the severity of ischaemia could be readily evaluated, and the possibility of attaining a long reperfusion period allowed us to distinguish between early and delayed reperfusion injury. These notable features of the preparation are of value for the investigation of ischaemic syndromes, for pharmacological and toxicological studies and, potentially, for the evaluation of the effects of genetic manipulation of the human myocardium. A number of aspects of our studies warrant further discussion.

\section{Stability of the preparation}

The in vitro model of the human right atrium characterized in the present studies has the major advantage of being stable for at least $24 \mathrm{~h}$ and it did not exhibit the rapid and gradual deterioration observed in other in vitro preparations during this period [22]. Thus for the first $24 \mathrm{~h}$ of incubation, tissue viability was not decreased and myocardial oxygen consumption and adenosine nucleotides were maintained at baseline values. However, by $48 \mathrm{~h}$ of incubation the preparation had deteriorated significantly, so that viability of the tissue was decreased to only $10 \%$, oxygen consumption by the atrial slices had decreased to less than $20 \%$ of the starting values, and the total adenosine nucleotides had decreased to $30 \%$ of the starting values. Morphological examination of the tissue also supported this thesis.

The stability of the preparation is also reflected by the profile of $\mathrm{LDH}$ leakage, an index widely accepted as a marker of tissue damage [23]. In both instances, there was a small but gradual leakage of $\mathrm{LDH}$ into the incubation media that, at first sight, could be interpreted as an indication of ongoing tissue injury; however, although this cannot be ruled out completely, it is most probably due to a physiological transmembrane movement of proteins and enzymes [24,25]. The massive LDH leakage observed at $48 \mathrm{~h}$ of incubation supports the argument that significant tissue damage has occurred by this time. 
A number of factors, including the temperature of the medium into which the atrial tissue is collected and processed, the slice thickness and the $\mathrm{PO}_{2}$ of the incubation media may affect the viability of the preparation. In preliminary studies (data not shown), we observed that all these factors play an important role in maintaining the stability of the preparation. To ensure stability, the temperature of the medium for the collection of the specimen should be $4-10^{\circ} \mathrm{C}$; for recovery and processing, the media temperature should be $37^{\circ} \mathrm{C}$ and the $P_{\mathrm{O}_{2}} 25-30 \mathrm{kPa}$, and the thickness of the slices should be no more than $0.5 \mathrm{~mm}$. These findings are supported by Paradise et al. [4] and Prasad and Callaghan [26], who reported that the thickness of the muscle preparation and the $\mathrm{PO}_{2}$ of the media are the determinants of the oxygen diffusion rate and the viability of the preparation. The small, not statistically significant decrease in tissue viability seen after the initial $30 \mathrm{~min}$ equilibration period, and associated with increased LDH leakage, is possibly the result of mechanical injury sustained during sectioning of the tissue. It is unlikely that ischaemic injury is a contributor to this phenomenon, because the procedure was carried out under hypothermic conditions and the time spent in processing the tissue samples was less than $2 \mathrm{~min}$, which is clearly insufficient time to induce myocardial damage. Furthermore, during this short period of sample processing, the muscles are not preconditioned when subjected to a long period of ischaemia [27].

\section{Studies on ischaemia}

To the best of our knowledge, the present study is the first to characterize the response of the human myocardium to various degrees of ischaemic insult. We have shown that a period of simulated ischaemia of only 30 min induced significant tissue injury, as measured by MTT reduction and LDH leakage, and that lengthening the ischaemic time to $2 \mathrm{~h}$ resulted in a loss of more than $75 \%$ viable tissue and substantial $\mathrm{LDH}$ leakage. It is worth noting that the decrease in oxygen consumption observed after $30 \mathrm{~min}$ of ischaemia was not further affected by 60 or $120 \mathrm{~min}$ of ischaemia. This suggests that, in fact, the remaining viable tissue augments oxygen consumption when compared with aerobically perfused tissue or with tissue subjected to shorter periods of ischaemia. This phenomenon of an oxygen-sparing effect after ischaemia has been described for several animal preparations [28-31], suggesting that it may not be a reliable index of tissue damage.

It is evident from these studies, not unexpectedly, that, although the atrial myocardial slices aerobically incubated for $24 \mathrm{~h}$ are still viable, they become more susceptible to ischaemic injury. This observation is of particular relevance when investigating the delayed effects of ischaemic syndromes, such as the second window of ischaemic preconditioning.

\section{Studies on reperfusion}

Our findings show that two different pictures can emerge from the injury sustained during reperfusion, depending on whether LDH leakage or MTT reduction are examined. On one hand, the absence of a significant net increase in $\mathrm{LDH}$ leakage over the $24 \mathrm{~h}$ reperfusion period compared with that seen during the first $2 \mathrm{~h}$ of reperfusion [compare Figure 9 (upper panel) with Figure 4] suggests that in our preparation tissue injury is limited to the initial $2 \mathrm{~h}$ reperfusion period. On the other hand, the results of the MTT reduction support the view that reperfusion injury is a progressive process throughout the $24 \mathrm{~h}$ reperfusion period. A possible explanation for this apparent discrepancy may be that LDH leakage represents enzyme loss from necrotic tissue, whereas MTT reduction reflects the loss of tissue viability via both necrosis and apoptosis. If this is the case, then one may be tempted to conclude that necrosis is confined to the early reperfusion period ( $\leqslant 2 \mathrm{~h}$ ), and that apoptosis is the main mechanism for the loss of tissue viability during the late reperfusion period. Support that apoptosis may play a role in the injury sustained during ischaemia and reperfusion comes from recent reports on different experimental preparations and animal species [32-34]. Certainly, more studies are required to clarify the role played by apoptosis in the ischaemia/reperfusion injury of the human heart. It is worth noting that the presence of blood components may influence the response and the degree of injury sustained during ischaemia/reperfusion. Our studies have shown that neutrophils may exacerbate late reperfusion injury and therefore the presence or absence of blood components should be taken into account when designing a study and interpreting the results.

The present model may facilitate the investigation of the underlying mechanisms of injury during early and delayed reperfusion in the human myocardium. This model will also allow us to elucidate the true effects of therapeutical interventions. By looking exclusively at the early reperfusion period, it is possible that many interventions, thought to be beneficial in the past, in fact may have limited therapeutic value if their action is delaying rather than reducing myocardial injury.

\section{Comparison with other preparations}

The use of in vivo or in vitro experimental models each has advantages and disadvantages but both are regarded as necessary and complementary. Thus, for example, in vivo models are useful to study the physiological relevance and long-term effects of the processes under investigation; however, they are complex and the influence of factors such as blood elements, the neuroendocrine system and even animal welfare and seasonal variations cannot be ruled out. By contrast, in vitro models are not exposed to the internal and external 
effects of living animals, but they are limited by their short duration (usually a few hours) and stability.

Studies on myocardial ischaemia in the clinical setting are difficult to carry out and to interpret and frequently they are ethically unacceptable. To overcome these difficulties, an alternative is the use of the right atrial preparations, such as the one described in the present study. Certainly, our right atrial preparation is relatively easy to use, the tissue is readily available and inexpensive, since it is regarded as 'surgical waste' in open-heart procedures, and, more importantly, it provides meaningful information on the human myocardium. The use of atrial tissue for studies of ischaemia may also offer advantages over isolated and cultured myocytes, because these are more difficult to obtain, they do not retain the normal cell-to-cell contact, ischaemia is more difficult to accomplish and they are viable only for short periods of time $[35,36]$. A notable benefit derived from the prolonged stability of our preparation is that the effects of reperfusion can be studied for a period that extends beyond the first few hours, which is usually not possible with in vitro preparations.

\section{Limitations of the preparation}

The present study has several limitations which need to be mentioned. First, the preparation is superfused ('simulated ischaemia') as opposed to being arterially perfused. However, the preclusion of the vasculature as the natural pathway for the provision of substrate may also be advantageous in that the confounding effects of the vascular changes and collateral flow induced by ischaemia and reperfusion are separated.

In the present study, atrial tissue was used to characterize the effects of ischaemia and reperfusion in the human myocardium. However, atrial and ventricular myocardium possess characteristics of their own that may influence the susceptibility to ischaemia/reperfusion injury and consequently the results from one may not be applicable to the other. Thus, for example, the reported differences in the distribution of potassium channels $[37,38]$, which contribute to the characteristic differences between atrial and ventricular action potentials, may determine a different response to ischaemia/reperfusion.

Although atrial tissue is generally stable and disease free, individual biological variations between patients may result in different susceptibility to ischaemia/ reperfusion injury and this must be accounted for when interpreting results from any human study.

\section{Conclusion}

We have characterized a model of ischaemia and reperfusion in the human myocardium using right atrial tissue obtained from patients undergoing cardiac surgery. This is readily available, the preparation is inexpensive and stable for at least $24 \mathrm{~h}$, which permits the study of the early and delayed consequences of ischaemia and reperfusion. In addition, the extended stability of the model may be potentially useful for genetic manipulation to investigate the pathophysiological mechanisms underlying injury sustained during ischaemia and reperfusion, and to develop new therapeutic strategies to combat the undesirable effects.

\section{ACKNOWLEDGMENTS}

This study was funded by grants from Heart Link and Link-up Charities, Glenfield Hospital NHS Trust and the University of Leicester. Our thanks to $\mathrm{Mr} \mathrm{T}$. Jefferson for his technical support with the morphological studies, Dr R. T. Smolenski for his analysis of the metabolite studies and Mr James Brown for his invaluable technical help with the Figures.

\section{REFERENCES}

1 Ikonomidis, J. S., Tumiati, L. C., Weisel, R. D., Mickle, D. A. G. and Li, R. K. (1994) Preconditioning human ventricular cardiomyocytes with brief periods of simulated ischemia. Cardiovasc. Res. 28, 1285-1291

2 Piper, H. M., Probst, I., Hutter, J. F. and Spieckermann, P. G. (1982) Culturing of calcium stable adult cardiac myocytes. J. Mol. Cell. Cardiol. 14, 397-412

3 Cleveland, Jr., J. C., Wollmering, M. M., Meldrum, D. R., Rowland, R. T., Rehring, T. F., Sheridan, B. C., Harken, A. H. and Banerjee, A. (1996) Ischaemic preconditioning in human and rat ventricle. Am. J. Physiol. 271, H1786-H1794

4 Paradise, N. F., Schmitter, J. L. and Surmitis, J. M. (1981) Criteria for adequate oxygenation of isometric kitten papillary muscle. Am. J. Physiol. 241, H348-H353

5 Cleveland, Jr., J. C., Meldrum, D. R., Cain, B. S., Banerjee, A. and Harken, A. H. (1997) Oral sulphonylurea hypoglycaemic agents prevent ischaemic preconditioning in human myocardium. Two paradoxes revisited. Circulation 96, 29-32

6 Rump, L. C., Schwertfeger, E., Schaible, U., Fraedrich, G. and Schollmeyer, P. (1994) Beta 2-adrenergic receptor and angiotensin II receptor modulation of sympathetic neurotransmission in human atria. Circ. Res. 74, 434-440

7 Rump, L. C., Berlit, T., Schwertfeger, E., Beyersdorg, F., Schollmeyer, P. and Bohmann, C. (1997) Angiotensin converting enzyme inhibition unmasks the sympathofacilitatory effect of bradykinin in human right atrium. J. Hypertens. 15, 1263-1270

8 Walker, D. M., Walker, J. M., Pugsley, W. B., Pattison, C. W. and Yellon, D. M. (1995) Preconditioning in isolated superfused human muscle. J. Mol. Cell. Cardiol. 27, 1349-1357

9 Cohen, G., Shirai, T., Weisel, R. D. et al. (1998) Optimal myocardial preconditioning in a human model of ischaemia and reperfusion. Circulation 98 (19 Suppl.), II-184-194; discussion II-194-196

10 Speechly-Dick, M. E., Grover, G. J. and Yellon, D. M. (1995) Does ischaemic preconditioning in the human involve PKC and the ATP-dependent $\mathrm{K}^{+}$channel ? Circ. Res. 77, 1020-1035

11 Auchampach, J. A., Grover, G. J. and Gross, G. J. (1992) Blockade of ischaemic preconditioning in dogs by novel ATP-dependent potassium channel antagonist sodium 5-hydroxydecanoate. Cardiovasc. Res. 26, 1054-1062

12 Gross, G. J. and Auchampach, J. A. (1992) Blockade of ATP-dependent potassium channels prevents myocardial preconditioning in dogs. Circ. Res. 70, 223-233 
$13 \mathrm{Li}$, Y. and Kloner, R. A. (1995) Does protein kinase C play a role in ischaemic preconditioning in rat hearts? Am. J. Physiol. 268, H426-H431

14 Schulz, R., Rose, J. and Heusch, G. (1994) Involvement of activation of ATP-dependent potassium channels in ischaemic preconditioning in swine. Am. J. Physiol. 267, H1341-H1352

15 Walker, D. M., Marber, M. S., Walker, J. M. and Yellon, D. M. (1994) Preconditioning in isolated superfused rabbit papillary muscles. Am. J. Physiol. 266, H1534-H1540

16 Yellon, D. M., Alkhulaifi, A. M. and Pugsley, W. B. (1993) Preconditioning the human myocardium. Lancet 342, 276-277

17 Zhang, J. G. and Lindup, W. E. (1993) Role of mitochondria in cisplatin-induced oxidative damage exhibited by rat renal cortical slices. Biochem. Pharmacol. $47,1127-1135$

18 Smolenski, R. T., Lachno, D. R., Ledingham, S. J. M. and Yacoub, M. H. (1990) Determination of sixteen nucleotides, nucleosides and bases using high-performance liquid chromatography and its application to the study of purine metabolism in hearts for transplantation. J. Chromatogr. 527, 414-420

19 Miyawaki, H., Zhou, X. and Ashraf, M. (1996) Calcium preconditioning elicits strong protection against ischemic injury via a protein kinase $\mathrm{C}$ signalling pathway. Circ. Res. 79, 137-146

20 Ashraf, M., Suleiman, J. and Ahmad, M. (1994) $\mathrm{Ca}^{2+}$ preconditioning elicits a unique protection against the $\mathrm{Ca}^{2+}$ paradox injury in rat heart, role of adenosine. Circ. Res. 74, 360-367

21 DeLeo, F. R., Renee, J., McCormick, S., Nakamura, M., Apicella, M., Weiss, J. P. and Nauseef, F. (1998) Neutrophils exposed to bacterial lipopolysaccharide upregulate NADPH oxidase assembly. J. Clin. Invest. 101, 455-463

22 Galiñanes, M. and Hearse, D. J. (1990) Species differences in susceptibility to ischaemic injury and responsiveness to myocardial protection. Cardioscience 2, 127-143

23 Hearse, D. J., Braimbridge, M. V. and Jynge, P. (1981) Protection of the Ischaemic Myocardium: Cardioplegia, Raven Press, New York

24 Hearse, D. J. (1980) Release of enzymes from ischaemic myocardium: Degradative problems in heart and skeletal muscle (Wildenthal, K., ed.), pp. 419-456, Elsevier, Amsterdam

25 Michell, R. H. and Coleman, R. (1979) Structure and permeability of normal and damaged membranes. Enzymes in Cardiology: Diagnosis and Research (Hearse, D. J. and De Leivis, J., eds.), pp. 59-79, John Wiley, Chichester
26 Prasad, K. and Callaghan, J. C. (1969) Effect of replacement of potassium by rubidium on the transmembrane action potential and contractility of human papillary muscle. Circ. Res. 24, 157-166

27 Ghosh, S., Standen, N. B. and Galiñanes, M. (2000)

Preconditioning the human myocardium with ischaemia. Studies on the early and delayed protection. Cardiovasc. Res. 45, 350-359

28 Buxton, D. B., Mody, F. V., Krivokapich, J. and Schelbert, H. R. (1993) Metabolism in non-ischaemic myocardium during coronary artery occlusion and reperfusion. J. Mol. Cell. Cardiol. 25, 667-681

29 Dean, E. N., Shlafer, M. and Nicklas, J. M. (1990) The oxygen consumption paradox of 'stunned myocardium' in dogs. Basic Res. Cardiol. 85, 120-131

30 Kawashima, S., Satani, A., Tsumoto, S., Kondo, T., Ikeoka, K., Motrita, M. and Iwasaki, T. (1991) Coronary pressureflow, pressure-function, and function-myocardial oxygen consumption relations in postischaemic myocardium. Cardiovasc. Res. 25, 837-843

31 Laxson, D. D., Homans, D. D., Dai, X. Z., Sublett, E. and Bache, R. J. (1989) Oxygen consumption and coronary reactivity in postischaemic myocardium. Circ. Res. 64, 9-20

32 Gottlieb, R. A., Burleson, K. O., Kloner, R. A., Babior, B. M. and Engler, R. L. (1994) Reperfusion injury induces apoptosis in rabbit cardiomyocytes. J. Clin. Invest. 94, 1621-1628

33 Maulik, N., Yoshida, T. and Das, D. K. (1998) Oxidative stress developed during the reperfusion of the ischaemic myocardium induces apoptosis. Free Radicals Biol. Med. 24, 869-875

34 Piot, C. A., Padmanaban, D., Ursell, P. C., Sievers, R. E. and Wolfe, C. L. (1997) Ischaemic preconditioning decreases apoptosis in rat hearts in vivo. Circulation 96, 1598-1604

35 Budinger, G. R. S., Chandel, N., Shao, Z. H., Li, C. Q., Melmed, A., Becker, L. M. and Schumacker, P. T. (1996) Cellular energy utilisation and supply during hypoxia in embryonic cardiac myocytes. Am. J. Physiol. 14, L37-L53

36 Tumiati, L. C., Li, R. K., Weisel, R. D., Williams, W. G. and Mickle, D. A. G. (1994) An in vitro model to study myocardial ischaemic injury. J. Tissue Culture Methods $16,1-9$

37 Amos, G. J., Wettwer, E., Metsger, F., Li, Q. and Himmel, H. M. (1996) Differences between outward currents of human atrial and subepicardial ventricular myocytes. J. Physiol. 491, 31-50

38 Heidbuchel, H., Vereecke, J. and Carmeliet, E. (1990) Three different potassium channels in human atrium: contribution to the basal potassium conductance. Circ. Res. 66, 1277-1286 